УДК 338.2:502(06)

\title{
УЧЕТ ЭКОЛОГИЧЕСКИХ ФАКТОРОВ В БИЗНЕС-ПЛАНИРОВАНИИ КАК РЕАЛИЗАЦИЯ ОПТИМАЛЬНОЙ ЭКОЛОГО-ЭКОНОМИЧЕСКОЙ СТРАТЕГИИ ФИРМЫ
}

\author{
(C) 2012 г. М. Л. Самсонова *, Л. Н. Исаенко** \\ *Новошахтинский филиал Южного федерального университета \\ ** ООО «Светлана 12», г. Шахты
}

\begin{abstract}
Рассматриваются методические аспекты организачии бизнес-планирования с учётом экологических факторов как критерия реализачии оптимальной эколого-экономической стратегии фирмыл.
\end{abstract}

Ключевые слова: бизнес-план; экономические и экологические факторы производства; эколого-экономический подход; стратегия развития фирмы; ассимиляционный потенциал; результаты производства.

Methodical aspects of business-planning organizing are considered from the standpoint of using the ecological factors as the criterion of developing the optimal ecological economic strategy of the company.

Key words: business plan; economic and ecological factors of the production; ecological and economics approach; company's development strategy; an assimilate potential; production results.

Современное производство, как правило, организованно по техногенному принципу. Оно по-прежнему использует технику и технологии, которые при производстве продукции и услуг формируют достаточно высокий удельный вес отходов производства, которые практически не используются в качестве вторичного сырья. Вследствие этого утилизация промышленных отходов, несмотря на использование различного рода очистных сооружений, по-прежнему предоставлена самой природе. При организации современного производства экологическому фактору придается второстепенный статус, вследствие чего ассимиляционный потенциал региона размещения предприятия практически не учитывается, что является одной из главных причин все возрастающей антропогенной нагрузки на природу, превышающей ее ассимиляционные возможности.

Одним из факторов данного процесса является техногенный характер бизнес-плани- рования. Современный подход к бизнес-планированию в качестве приоритета определяет максимизацию экономических результатов производства, вследствие чего учет экологических факторов является зачастую формальным. Поэтому используемые сегодня методологические подходы к организации бизнеспланирования не могут эффективно сочетать экономические интересы производителя и общества с оптимальными объемами загрязнения окружающей среды, поскольку при планировании производства экологический фактор не является определяющим в организации производства. Он не обуславливает потребности в поисках более экологически совершенных технических, технологических и организационных вариантов производства. Главный ориентир современного производства - прибыль, что и определяет содержание и последовательность методики разработки бизнес-плана (рис. 1). Данная методика обуславливает «подтягивание» экологических 
результатов производства к требуемым собственником, менеджером экономическим результатам.

Выход из данной ситуации, на наш взгляд, возможен при изменении методологии и методики бизнес-планирования. Во-первых, экономические результаты не должны быть главным ориентиром развития производства, им являются экологические нормативы, определяющие объем производства исходя из допустимых объемов загрязнения в регионе размещения предприятия. Во-вторых, масштабы организации и развития производства должны определяться, в первую очередь, используемыми техническими, технологическими и организационными факторами позволяющими соблюдать экологические нормативы загрязнения и не выводящими объемы загрязнения окружающей среды за рамки ассимиляционного потенциала региона. Втретьих, данный подход позволит ориентировать предприятия на поиск более гибких технических, технологических и организационных факторов производства - малоотходные и безотходные технологии, которые по сравнению с применяемыми очистными сооружениями являются более гибкими по отношению к росту объема производства.

Последовательность разработки бизнесплана с учетом данных требований представлена на рис. 2.

Первостепенность экологических факторов производства над экономическими меняет процесс организации бизнес-планирования на предприятии: в данном случае происходит переориентация целей производства с достижения максимальных экономических результатов на поиск оптимальных экологоэкономических. Изначально процесс планирования производства начинается с показателей ПДВ и ПДС, определяющих возможный экологически обоснованный объем производства продукции и услуг при использовании планируемых технических и технологических решений производства. Рост объема производства может быть только при внедрении новых более экологичных технических, технологических и организационных решений. Например, при нахождении потребителей отходов данного производства использующих их как вторичное сырье.

Предлагаемый подход к организации биз-

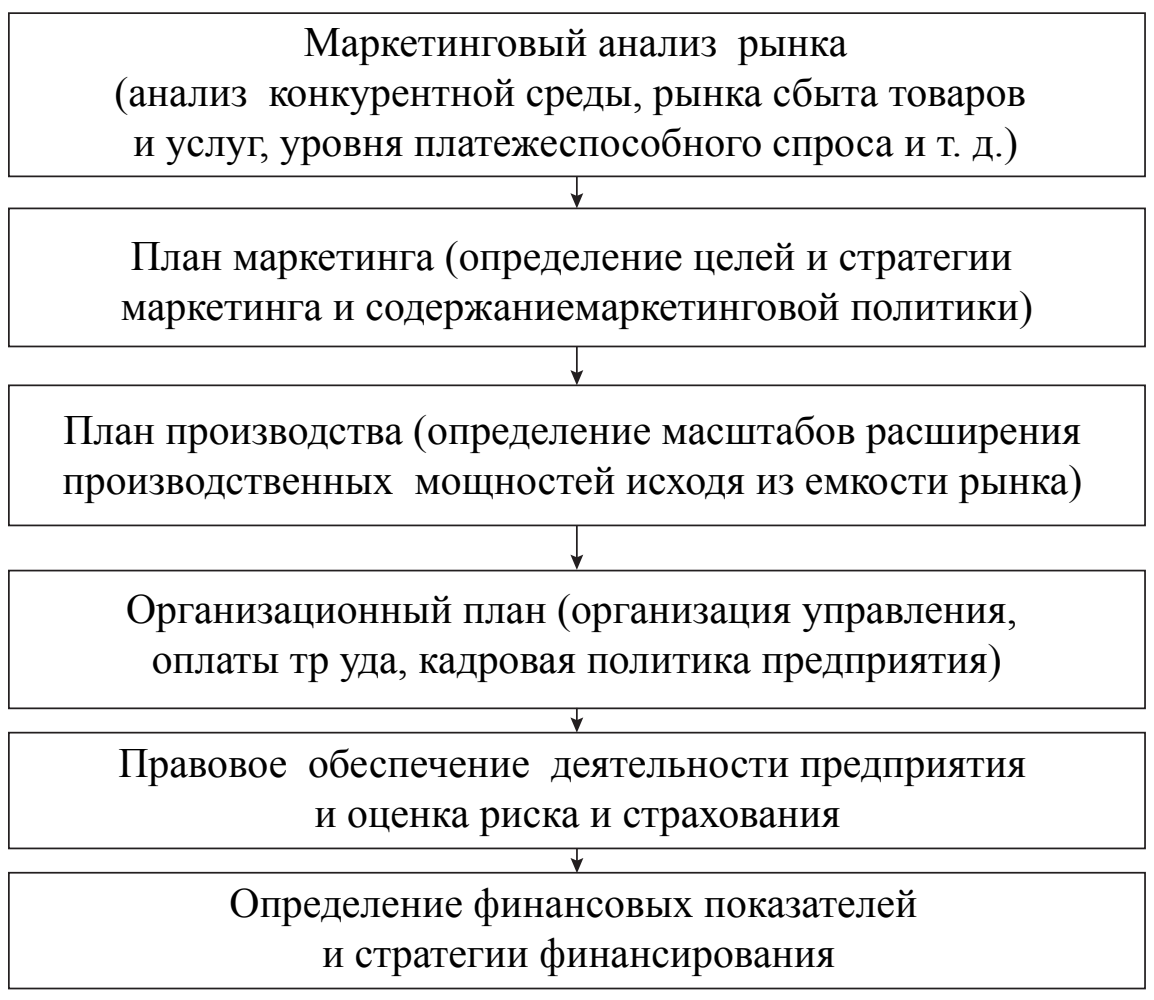

\begin{tabular}{|c|}
\hline Экологический \\
паспорт \\
предприятия \\
\hline
\end{tabular}

Рис. 1. Традиционная последовательность разработки бизнес-плана 


\begin{tabular}{|c|c|}
\hline $\begin{array}{c}\text { Экологический анализ } \\
\text { (анализ экологических показателей окружающей среды } \\
\text { региона размещения предприятия) }\end{array}$ & \multirow{3}{*}{$\begin{array}{c}\text { Маркетинговый } \\
\text { анализ рынка } \\
\text { (анализ } \\
\text { конкурентной } \\
\text { среды, рынка } \\
\text { сбыта товаров и } \\
\text { услуг, уровня } \\
\text { платежеспособного } \\
\text { спроса и т. д.) }\end{array}$} \\
\hline $\begin{array}{c}\text { Расчет экологических параметров допустимых } \\
\text { для данного предприятия }\end{array}$ & \\
\hline $\begin{array}{c}\downarrow \\
\text { Определение основных показателей } \\
\text { Экологического паспорта предприятия }\end{array}$ & \\
\hline \multicolumn{2}{|c|}{$\begin{array}{c}\text { Выбор технологических процессов и подхода к организации производства } \\
\text { отвечающих требованиям и критериям рационального природопользования, } \\
\text { обеспечивающих рациональное сочетание экономических интересов предприятия } \\
\text { и экологических стандартов }\end{array}$} \\
\hline \multicolumn{2}{|l|}{$\downarrow$} \\
\hline \multicolumn{2}{|c|}{$\begin{array}{c}\text { План маркетинга } \\
\text { (определение целей и стратегии маркетинга и содержание маркетинговой политики) }\end{array}$} \\
\hline \multicolumn{2}{|c|}{$\begin{array}{c}\text { План производства } \\
\text { (определение масштабов расширения производственных мощностей исходя } \\
\text { из ёмкости рынка) }\end{array}$} \\
\hline \\
\hline \multicolumn{2}{|c|}{$\begin{array}{c}\text { Организационный план } \\
\text { (организация управления, оплаты труда, кадровая политика предприятия) }\end{array}$} \\
\hline \multicolumn{2}{|l|}{$\downarrow$} \\
\hline \multicolumn{2}{|c|}{ Правовое обеспечение деятельности предприятия и оценка риска и страхования } \\
\hline & \\
\hline ансовых показателей & иров \\
\hline
\end{tabular}

Рис. 2. Последовательность разработки бизнес-плана с учетом экологических факторов

нес-планирования позволяет интегрировать его с оптимальной эколого-экономической стратегией развития фирмы. Современные реалии таковы, что одним из главнейших приоритетов общественного прогресса остаётся поиск путей оптимизации сосуществования с экосистемой, которая по-прежнему является базой развития общества. Определяя стратегию своего развития с учетом экологических аспектов предприятие свои текущие планы должно разрабатывать по аналогичному принципу. Соответственно, предлагаемый нами подход к бизнес-планированию позволяет на стадии планирования определить пути преодоления антагонизма производства и окружающей среды, а также определить содержание текущих планов исходя из направлений перспективной эколого-экономической стратегии развития предприятия.

\section{Литература}

1. Гуров В. Г. Бизнес-план как условие стратегического развития организации. // Вестник Российского государственного гуманитарного университета. - 2011. — №4. C. $121-128$.

2. Исаенко Л. Н. Оптимизация эколого-экономических факторов производства - основа регионального регулирования 
социально-экономическими процессами. // Социально-экономические и правовые вопросы современного российского общества: сб. науч. ср. / Шахтинский ин-т ЮРГТУ (НПИ). — Новочеркасск: УПЦ «Набла», ЮРГТУ (НПИ), 2005. - С. 162-165.

3. Исаенко Л. Н. Эколого-экономическая эффективность - критерий развития отрасли. // Горный информационно-аналитический бюллетень (научно-технический жур- нал). - 2008. - Т. 1. - №1. - С. 225-230.

4. Осинкевич Л. М. Экономические механизмы рыночного природопользования. // Вестник Курской государственной сельскохозяйственной академии. - 2008. - №3. C. 68-71.

5. Сокушева Л. Г., Щукина Е. С. Экономический механизм природопользования. // Вестник ОГУ. — 2006. - №8. - С. 81-88.

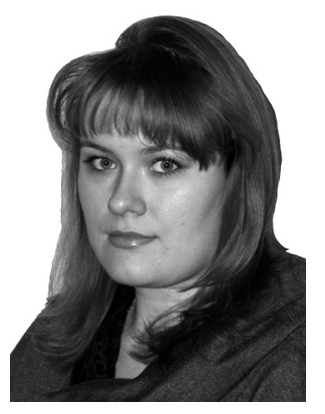

Мария Леонидовна Самсонова - ассистент кафедры Экономики и менеджмента Новошахтинского филиала Южного федерального университета.

Maria Leonidovna Samsonova - assistant lecturer at the Economy and Management department of Southern Federal University's Novoshakhtinsk branch.

346900, Ростовская обл., г. Новошахтинск, ул. 40 лет Октября, 2

240 let Oktyabrya st., 346900, Novoshakhtinsk, Rostov reg., Russia

Тел.: +7 (86369) 2-33-24; e-mail: novoshahtinsk@sfedu.ru

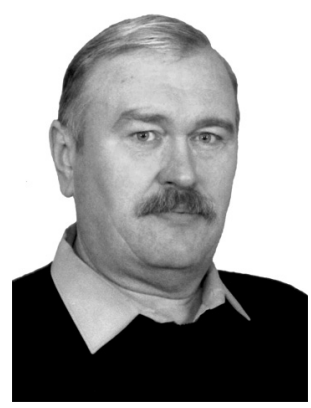

Леонид Николаевич Исаенко - кандидат экономических наук, директор ООО «Светлана 12».

Leonid Nikolayevich Isaenko - Ph.D., Candidate of Economics, director of «Svetlana 12» public corporation.

346900, Ростовская обл., г. Новошахтинск, ул. 40 лет Октября, 2 240 let Oktyabrya st., 346900, Novoshakhtinsk, Rostov reg., Russia

Тел.: +7 (86369) 2-33-24; e-mail: novoshahtinsk@sfedu.ru 